\title{
La imagen de la arquitectura asturiana de los siglos VIII y IX en las crónicas de Alfonso III
}

\author{
Victor Nieto ALCAIDE
}

Durante el reinado de Alfonso III (866-910) se redactaron varias crónicas a través de las cuales la monarquía asturiana emprende la continuación de una tradición historiográfica que habia quedado interrumpida, según todos los indicios, desde la invasión musulmana ${ }^{1}$. El estudio de las tres crónicas que forman el llamado "Ciclo de Alfonso III" , Crónica Albeldense, y Crónica de Alfonso III, en sus dos versiones "Rotense" y "A Sebastian", ha puesto de manifiesto como la intención que movió a su redacción fue demostrar que el reino asturiano era el legítimo continuador del visigodo de Toledo convirtiendo en lógicas y lícitas las pretensiones de Alfonso III por recuperarlo y dominar la Península ${ }^{3}$. A través de ello, se propone un planteamiento ideológico tendente a justificar como Reconquista lo que, en realidad, era una conquista. $Y$ esta idea, cuya justificación subyacente se desarrolla en las crónicas, se convierte en un principio que alcanza, en el marco expansionista de la política de este soberano, una importancia capital.

1 C. Sanchez Albornoz, En torno a los orígenes del Feudalismo, Mendoza, 1942, II, pág. 100-101, ha supuesto la existencia de una crónica anterior perdida, escrita hacia el año 800; R. MENÉNDEZ PIDAL, "La historiografía medieva! sobre Alfonso ll», Estudios sobre la Monarquia Asturiana, Oviedo, Instituto de Estudios Asturianos, 1971, pág. 12

2 M. Gomez Moreno, "Las primeras crónicas de la Reconquista. El ciclo de Alfonso III", Boletín de la Real Academia de la Historia, C, (1932), pág. 562.627.

3 A. BARBero y M. ViGil, "La historiografía de la época de Alfonso III", La formación del Feudalismo en la Península Ibérica, Barcelona, Editorial Crítica, segunda edición, 1979, pág. 233. 
En relación con esta idea se aprecia en las crónicas una tendencia a establecer una sucesión directa y sin solución de continuidad con el reino visigodo de Toledo que, desde un punto de vista histórico actual, ha sido rechazada ${ }^{4}$. A este respecto, Menéndez Pidal ${ }^{5}$ ha observado como la mencionada continuidad se hace patente en los mismos títulos de las crónicas. Las dos versiones de la Crónica de Alfonso III se rotulan Chronica Visigothorum, "desde tiempo del rey Wamba hasta ahora, el tiempo del glorioso rey Ordoño" (a tempore Bambani regis usque nunc in tempore Gloriosi Ordoni regis...), en la versión "Rotense" y "desde el tiempo del rey Wamba hasta ahora, tiempo del glorioso rey Garcia" (a tempore uuambani regis usque nunc inj tempore Gloriosi Garseani regis) en la versión "A Sebastian". Por su parte el autor de la Crónica Albeldense titula la serie de reyes asturianos "Sucesión de los Reyes Godos de Oviedo" (Ordo Gotorum Obetensium Regum). Lo que equivalia imaginar el reino asturiano como una sucesión legítima y sin solución de continuidad con respecto al visigodo de Toledo. A esto mismo se debe que, en la versión corregida “A Sebastian» de la Crónica de Alfonso III, se subraye la continuidad visigoda de Pelayo y Alfonso I, trocando la elección del primero por los astures en una elección de godos, algunos de sangre real, refugiados en Asturias ${ }^{6}$.

Dentro de este contexto, se introduce en las crónicas otro aspecto que participa de esta misma concepción ideológica y que será objeto de estudio en estas páginas. Me refiero a la imagen que configura este ciclo historiográfico en torno a los edificios construidos por los reyes asturianos.

Siempre ha llamado la atención la minuciosidad y extensión con que se hace referencia en estas crónicas a los edificios asturianos. Se trata de uno de los puntos de coincidencia de la Crónica Albeldense con la Crónica de Alfonso $1{ }^{7}{ }^{7}$ introduciendo un «tema arquitectónico que el estilo cronístico no solía tratar y que sin duda estaba impuesto por el gusto particular de Alfonso III, apasionado por las edificaciones" ${ }^{8}$. Es cierto, que este aspecto pudo influir la voluntad del monarca pero, en nuestra opinión, no fue solamente una cuestión de gusto o preferencia artistica.

4 A. Barbero y M. Vigll, obra citada, pág. 235.

5 R. Menendez Pidal, Historia de España. España cristiana. Comienzo de la Reconquista (711-1038), Madrid, Espasa-Calpe, 1971, Tomo VI, pág. X-XI. pág. 236.

R. Menendez Pidal, obra citada, pág. IX; A. Barbero y M. Vigil, obra citada,

R. Menéndez Pidal, obra citada, pág. IX.

8 Ibidem. 
Su inserción en las crónicas creemos que tiene otro alcance relacionado con la suma de intenciones que movieron al monarca a emprender este programa historiográfico. Asi lo confirma el sentido laudatorio de algunas menciones, que analizaremos más adelante, relativas a los edificios construidos por los reyes.

La primera mención que nos interesa analizar aqui aparece en la versión "Rotense" de la Crónica de Alfonso III, acreditando en el nuevo reino una temprana actividad constructiva regia. En Cangas de Onis, según la citada crónica, Fávila «Edificó, en una obra admirable, una basílica en honor de la Santa Cruz" (Basilicam in honore sancte Crucis miro opere constru$x_{i t)}{ }^{9}$. La veracidad de esta noticia, que se silencia en la versión corregida de esta crónica ( A Sebastian») y que tampoco aparece en la Crónica Albeldense, está confirmada por una inscripción, hoy perdida, según la cual, en el año 737, el rey Fávila con su esposa Froliuba erigieron una iglesia que fue consagrada por el sacerdote Asterio ${ }^{10}$.

La iglesia fue construida sobre un dolmen en el lugar en el que, probablemente, ya existía culto cristiano con anterioridad, acreditado en la región por la existencia de ciertos establecimientos cenobíticos ${ }^{11}$. No corresponde aquí analizar el problema que presenta, en este sentido, la construcción de este edificio, sino los aspectos que suscita, en relación con los orígenes del arte asturiano, la mención que acabamos de transcribir. Para ello conviene tener presente que no debe ser algo casual el silencio de la Crónica Albeldense ni que la mención aparezca en la primera versión («Rotense») de la Crónica de Alfonso III desapareciendo en la versión corregida de esta crónica ("A Sebastian»), más próxima al

9 Crónicas Asturianas. Crónica de Alfonso III (Rotense y "A Sebastian"). Crónica Albeldense ( $y$ "Profética"). Introducción y edición crítica de J. Gil Fernandez. Traducción y notas de J. L. Moralejo. Estudio preliminar J. I. RuIz de LA Peña. Oviedo, Universidad de Oviedo, 1985, 11, pág. 130 y 206. Obra citada, de ahora en adelante, como Crónicas Asturianas.

10 Sobre la inscripción veáse C. M. VIGIL, Asturias Monumental, Epigráfica y Diplomática. Datos para la Historia de la Provincia, Oviedo 1887, pág. 30; A. Floriano Cumbreño, Restauración del culto cristiano en Asturias en la iniciación de la Reconquista. Discurso leído en el acto de su solemne recepción académica... Contestación del $\mathrm{M}$. I. señor don José María Fernández Buelta. Oviedo, Instituto de Estudios Asturianos, 1949, pág. 34-35. J. VIVES, Inscripciones cristianas de la España romana y visigoda, Barcelona 1969, núm. 315, pág. 107.

"F. ÍñIGUEZ ALMECH, "Algunos problemas de las viejas iglesias españolas", Cuadernos de Trabajos de la Escuela Española de Historia y Arqueología en Roma, VII, (1955), pág. 9 y siguientes; A. BARBERO y M. VIGIL, "La organización social de los cántabros y sus transformaciones en relación con los orígenes de la Reconquista", Sobre los origenes sociales de la Reconquista, Barcelona, Ariel, 1979, pág. 190 y ss. 
pensamiento del rey, en la que se excluye, debido seguramente a su escasa importancia, la noticia incluida en la primera redacción.

La noticia atestigua dos fenómenos que alcanzarán un profundo arraigo en la monarquía asturiana: la iniciativa regia como impulsora de programas arquitectónicos y el culto a la Santa Cruz que alcanza desde la época de Alfonso Il la categoría de un símbolo y un signo de identidad del reino. Este aspecto se vio refrendado de forma muy especial en la época de Alfonso III, cuyas construcciones ostentan el simbolo de la cruz como un componente indisolublemente unido a la idea del poder y de la monarquía ${ }^{12}$. Sin embargo, a pesar de la veracidad de la noticia, el cronista exagera al calificar la iglesia de "obra admirable», hallándose en contradicción con las características reales que tuvo el edificio según indica el texto de la mencionada inscripción en la que se le califica de "obra modesta" o "pequeña" (opere exiguo). A lo inexacto de esta noticia parece referirse Ambrosio de Morales, que llegó a ver el edificio, cuando, en su Crónica, no duda en afirmar que «No hay nada en ella que merezca el encarecimiento de maravillosa labor, pues es toda una silleria lisa, sino que es algo grande, y tiene, a la costumbre de entonces otra del mismo tamaño debaxo. Esto deberia bastar por entonces para celebrar con tanta demasía aquella fábrica” ${ }^{13}$.

La noticia de la crónica apunta la idea de que desde sus comienzos los monarcas asturianos habían desarrollado un proceso constructivo apenas interrumpido con respecto al visigodo, aplicando el calificativo de "obra admirable" a un edificio de exiguas dimensiones y modesta construcción. Incluso es probable que el cronista no hubiera llegado siquiera a ver la mencionada iglesia aplicando el mismo calificativo que hallamos en la descripción de otros edificios construidos por Alfonso II, en la sedes regia de Oviedo. Así, también en la versión "Rotense" de la Crónica de Alfonso III, a propósito del panteón regio de Santa María, se dice que es «obra admirable» (Miro opere) ${ }^{14}$. Esta expresión también la hallamos en

12 Sobre el culto a la cruz véase A. Floriano Cumbreño, obra citada, pág. 11 y ss.; F. J. Fernandez Conde, La Iglesia de Asturias en la Alta Edad Media, Oviedo, Instituto de Estudios Asturianos, 1972, pág. 32-33. Acerca de las lápidas con la cruz procedentes de edificios ovetenses y conservadas en el Museo Arqueológico de Oviedo, véanse los trabajos de J. URIA RIu, "Cuestiones Histórico-Arqueológicas relativas a la Ciudad de Oviedo de los siglos vil al X", Symposium sobre Cultura Asturiana de la Alta Edad Media, septiembre, 1961, Oviedo, Excelentisimo Ayuntamiento, 1967, pág. 261-328 y H. Rodriguez BalBin, De un monte despoblado a un Fuero real 700-1145. Estudio sobre los primeros siglos del desarrollo urbano de Oviedo, Oviedo, Universidad de Oviedo, 1977, pág. 145 y ss.

13 Libro XIII, Cap. IX, 1.

14 Crónicas Asturianas..., 21, pág. 140. 
la versión corregida (“A Sebastian») a propósito de la iglesia del Salvador (miro construxit opere) ${ }^{15}$.

Esta posible intención de las crónicas por establecer una continuidad entre el desaparecido reino visigodo y el nuevo reino astur se ha planteado, también en la historiografía moderna al acometer el problema de los origenes del arte asturiano ${ }^{16}$. De esta manera, aunque de la iglesia construida por Fávila y su esposa Froliuba, demolida en 1632, solamente poseemos la transcripción de una inscripción y la noticia de una crónica, se ha pretendido ver como un nexo entre la arquitectura visigoda y el inicio de la asturiana.

En la mencionada inscripción se dice: "Resplandezca con intensa claridad ante la mirada sagrada este templo mostrando el signo de la Cruz. Que sea del agrado de Cristo este edificio consagrado bajo el trofeo de la cruz que construyó con ostensible fe el siervo Fávila con su esposa Froliuba..." ${ }^{17}$ (Perspicue clareat oc templum obtutibus sacris demonstrans figuraliter signaculum alme crucis sit Christo placens ec aula sub crucis tropheo sacrata quam famulus Fafefila sic condidit fide prompta cum Froliuva) ${ }^{18}$. Lo cual ha dado lugar a que se haya supuesto que la iglesia tendría planta cruciforme siguiendo una tradición visigoda ${ }^{19}$, como las de las iglesias de Santa Comba de Bande y San Pedro de la Mata ${ }^{20}$, o como la primera y San Fructuoso de Montelios ${ }^{21}$. Con ello se

15 Crónicas Asturianas..., 21, pág. 139.

16 De este aspecto me ocupé en mi estudio Arte prerrománico asturiano, SaLINAS, Ayalga Ediciones, 1989. Para una información más amplia sobre el arte asturiano remito al repertorio publicado por R. Bordu Cienfuegos-Jovellanos, Inventario Documental y Bibliográfico sobre el Prerrománico Asturiano, Oviedo, Principado de Asturias, Consejería de Educación, Cultura y Deportes, 1989.

17 A. Floriano Cumbreño, obra citada, pág. 11-12.

18 C. M. VigIL, obra citada, pág. 305.

19 L. Torres Balbas, «El arte de la Alta Edad Media y del período románico en España", en M. Hauttmann, Arte de la Alta Edad Media, Barcelona, Editorial Labor, 1934, pág. 162; L. PUIG Y CADAFALCH, L'Ait wisigothique et ses survivances. Recherces sur les origines et le développemente de l'Art en France et en Espagne du Vle au XIle siécle, Paris 1961, pág. 90; A. Floriano Cumbreño, obra citada, pág. 11; C. CiD Priego, "Las artes del prerrománico asturiano", Asturias, Tierras de España, Madrid-Barcelona 1978, pág. 150151; M. NúNEZ, "El ayer de Asturias durante los tres siglos de dominación germánica", Boletín del Instituto de Estudios Asturianos, núm. 108, (1983), pág. 68; M. BERENGUER, “El templo de Santa Cristina de Lena (Asturias); sus posibilidades como construcción visigoda", en Boletín del Instituto de Estudios Asturianos, núm. 112, (1984), pág. 741 y ss; J. DoDDs, "Las pinturas de San Julián de los Prados. Arte, diplomacia y herejía", Goya, núm. 191, (1986), pág. 258.

${ }_{20}$ H. SCHLUNK, "Spanische Architektur aus der Zeit der asturischen Monarchie", Forschungen und Fortschritte, núms. 20-21, 16-20 de julio de 1937, pág. 241 , alude a estas iglesias como precedente pero inicia el análisis de la arquitectura asturiana con San Julián 
ha pretendido acreditar, desde muy temprano, la existencia de una actividad constructiva que continuaria, sin solución de continuidad, la tradición arquitectónica visigoda.

Nada hay, sin embargo, en la inscripción que permita suponer que la planta de esta iglesia fue cruciforme. El texto a lo que hace referencia es a la idea simbólica de la cruz en una iglesia consagrada a su culto en la que existiria una pieza con este signo. Ambrosio de Morales, a este respecto, es muy preciso en su forma de interpretar la inscripción cuando afirma que «...lo que dice en substancia es como el Rey, por instinto divino mandó edificar aquella iglesia, la dedicó por trofeo de la Santa Cruz y puso su imagen en ella» ${ }^{22}$.

Por las menciones citadas nada podemos saber acerca de como fue la iglesia de Santa Cruz de Cangas de Onís ni afirmar si tuvo o no planta de cruz y, mucho menos, que sería como las de las iglesias visigodas citadas. Porque, en realidad, en estas interpretaciones lo que subyace es un intento de enfocar el origen del arte asturiano como una prolongación del visigodo, cuando, en realidad, fue algo bien distinto claramente desligado de las tradiciones godas ${ }^{23}$.

Es evidente que las crónicas del ciclo de Alfonso III surgieron como consecuencia de unas exigencias y unos intereses políticos concretos de la monarquia asturiana. Fundamentalmente, según dijimos, suponían un soporte ideológico y legitimador de la política expansionista a que obedecía la idea de "Reconquista". A través de ello se planteaba una aparente contradicción a causa de que "en un Estado que surge en unas regiones no dominadas por los visigodos, ni asimiladas dentro de las estructuras del reino de Toledo, se adoptará luego la tradición gótica como ideología oficial» ${ }^{24}$.

de los Prados. De este trabajo se publicó una traducción con el título, "La arquitectura española del tiempo de la monarquía asturiana", Investigación y Progreso, XI, 1940, pág. 69-74. Este autor, en un trabajo posterior, "Arte visigodo. Arte asturiano", Ars Hispaniae, vol. II, Madrid, Editorial Plus Ultra, 1947, pág. 327, señala el parentesco citado de la iglesia de Santa Cruz de Cangas de Onís con Santa Comba de Bande y San Pedro de la Mata. Esta misma suposición la mantiene J. M. PITA Andrade, Arte Asturiano, Madrid, Consejo Superior de Investigaciones Científicas, 1963, pág. 10. Por su parte, A. Bonet CorREA, Arte Prerrománico Asturiano, Barcelona, Polígrafa, 1967, pág. 84 , ha notado los inseguros fundamentos en que sustenta esta suposición.

${ }^{21}$ P. DE PALOL, L'Art en Espagne du royaume wisigothique á la fin de l'époque romane,

París, Flammarion, 1967, pág. 84.

${ }_{22}$ Crónica, Libro XIII, Cap. IX, 2.

23 Remito de nuevo a mi trabajo citado en la nota núm. 16.

${ }^{24}$ A. Barbero y M. Vigil, La Historiografía..., pág. 236. 
A este respecto, la Crónica Albeldense contiene, en relación con este problema, una referencia que debemos estudiar con cierto detenimiento. El cronista, al referirse a las iglesias construidas por Alfonso II (791-842) en Oviedo, dice: "y todas estas casas del Señor las adornó con arcos y con columnas de mármol, y con oro y plata, con la mayor diligencia y, junto con los regios palacios, las decoró con diversas pinturas; $y$ todo el ceremonial de los godos, tal como había sido en Toledo, lo restauró por entero en Oviedo, tanto en la iglesia como en el palacio" (omnesque has Domini domos cum arcis atque columnis marmoreis auro argentocue diligenter ornauit, simulque cum regiis palatiis picturis diversis decorauit; omnemque Gotorum ordinem sicuti Toleto fuerat, tam in eclesia quam palatio in Ouetao cuncta statuit) ${ }^{25}$.

Las referencias artísticas que nos transcribe la Crónica Albeldense son precisas. Es cierto que algunas no podemos comprobarlas por haber desaparecido los edificios a que hacen referencia como es el caso de los palacios. Pero otras encuentran su verificación en edificios que han llegado a nosotros, como San Julián de los Prados y su decoración de pinturas. También, coinciden con la descripción que hace Ambrosio de Morales de un edificio perdido como el panteón regio de Santa María. Este autor, refiriéndose a las capillas de la cabecera, dice que "Todas tres estan labradas con hermosa proporción y correspondencia, adornadas de grandes y de ricos mármoles a las entradas y dentro para formar y sustentar las bóvedas de otros más pequeños que son por todos doce de diversos colores" ${ }^{26}$.

El texto de la crónica, por otra parte, alude con claridad a como Alfonso Il restauró en el palacio y en la iglesia el ceremonial de los godos, lo cual no permite suponer que se trate, tal y como se ha hecho, de una referencia que acredita un neovisigotismo artístico ${ }^{27}$. Primero, porque el texto no hace referencia a este problema sino a aspectos administrativos, políticos y religiosos. $Y$, en segundo lugar, porque si fuera una referencia a lo artístico ésta no pasaría de ser una suposición imaginaria y evocadora de un modelo que sólo mentalmente alcanzó la categoria de un ideal. Otras menciones de las crónicas, que serán analizadas más adelante, contradicen con claridad el supuesto de un "revival» de las formas artísticas visigodas al apuntarse en ellas la idea de una "superación” de éstas.

${ }^{25}$ Crónicas Asturianas..., XV, 9, pág. 248-49 y 174.

26 Crónica, Libro XIII, Cap. XL, 1.

27 I. BANGO TORVISO, "El neovisigotismo artístico de los siglos $\mathrm{x}$ y $\mathrm{x}$ : La restauración de ciudades y templos", Revista de Ideas Estéticas, 1979, pág. 319-20 
Las construcciones llevadas a cabo por Alfonso II configuraron Oviedo como una sedes regia en la que se desarrolla por primera vez en et reino asturiano una imagen de prestigio. Con ella, además se establecía en el plano político e ideológico una primera confirmación del mito de la continuidad visigoda al concebirse Oviedo como una "Nueva Toledo" superadora de la capital del antiguo reino visigodo.

Bajo Alfonso II el "neovisigotismo" se afirma como un modelo politico, ideológico y burocratico. En cambio, los edificios construidos por este soberano nada tienen que ver con este fenómeno. Bajo Alfonso II, a diferencia de lo que luego sucederá con Alfonso III - bajo cuyo reinado se piensa trasladar la corte a León- Oviedo se configura como una sedes regia definitiva y estable. Así lo confirma el programa arquitectónico llevado a cabo por el rey Casto: catedral de San Salvador, Palacio y Capilla Relicario (Cámara Santa), Panteón regio de Santa María y San Tirso, cuya dedicación establecía una alegoría de las virtudes del soberano. $Y$ todo ello protegido por una cerca fortificada ${ }^{28}$ que delimitaba este conjunto de la hierápolis, no lejos de la cual se hallaba la residencia e iglesia regia suburbana de Santullano. De lo conservado de este programa nada permite suponer que se llevó a cabo un "revival» de las formas artísticas visigodas. A lo sumo, lo que se produjo fue una emulación, utilizando formas artísticas nuevas, y, como puede deducirse de la lectura de la crónica, el nacimiento de la idea de que Oviedo era la capital de un reino sucesor del visigodo de Toledo.

En relación con este problema no debe olvidarse que en la época de Alfonso II se produce la querella contra el adopcionismo cuya doctrina se habia extendido por la España dominada por los musulmanes. Condenada por el Papa Adriano I y combatida por Carlomagno y Alfonso II ${ }^{29}$, esta herejia supuso para el soberano astur la ocasión de emanciparse de las ligaduras de la iglesia de Toledo creando, con anterioridad al año $812^{30}$, su propia diócesis de Oviedo. $\mathrm{Y}$, en este sentido, pienso que es muy probable que sea este uno de los aspectos a los que se refiere $\mathrm{El}$ texto antes transcrito de la Crónica Albeldense.

En relación con este aspecto, el "neovisigotismo" de Alfonso II hay que asociarlo con la idea de la traslatio. Durante la Edad Media la Biblia

${ }^{28}$ Sobre el problema del perimetro de la cerca véase $H$. Rodriguez Balbin, obra citada, pág. 133 y ss.

${ }_{29}$ Sobre la repercusión de la actitud antiadopcionista de Alfonso II en sus programas artísticos, véase J. DODDS, obra citada.

30 F. J. Fernández Conde, obra citada, pág. 38. 
proporcionó al pensamiento histórico "una razón teológica para la sucesión de un reino por otro" ${ }^{31}$. Así, por ejemplo, en el Eclesiástico se dice como «El imperio pasa de unas naciones a otras por las injusticias, la ambición y la avaricia” ${ }^{32}$. De este y otros textos análogos surge la fundamentación de la idea de traslatio. Y no es preciso insistir acerca de la creencia de que la perdida del reino visigodo de Toledo obedeció a la ambición y a luchas internas. La Crónica de Alfonso III hace referencia en sus dos versiones a la causa de la pérdida del reino visigodo de Toledo por la traición. La versión "Rotense» dice como el rey Rodrigo salió al encuentro de los invasores «Pero, aplastados por la muchedumbre de sus pecados y traicionados por el fraude de los hijos de Vitiza, fueron puestos en fuga" (Sed suorum peccatorum classe oppresi et filiorum Vitizani fraude detecti in fuga sunt uersi) ${ }^{33} \mathrm{Y}$ en términos similares se expresa el autor de la versión corregida "A Sebastian": «Pero como la Escritura dice: En vano corre aquel a quien la iniquidad precede, aplastados por la mole de los pecados de los obispos y de los suyos propios, y traicionados por el fraude de los hijos de Vitiza, todos los ejércitos de los godos se dieron a la fuga y fueron aniquilados por la espada" (Sed dicente scriptura in vanun currit quem iniquitas precedit, sacerdotum uel suorum peccatorum mole oppressi uel filiorum uittizuani fraude detecti, comne agmen Gotorum in fugam sunt uersi et gladio deleti) ${ }^{34}$.

En este sentido, Oviedo surge como una nueva ciudad en la que establece la traslatio de todo el poder, aparato, estructura poliica, administrativa y religiosa del desaparecido reino. La sedes regia del nuevo reino astur surgía, de esta manera y por designio divino, como una Toletus nova de la que también tiene que depender la iglesia española ${ }^{35}$. $Y$, también, como un símbolo en el que se plasma, como veremos más adelante, el ideal y la utopía de la superación del extinguido reino visigodo.

En las crónicas del ciclo de Alfonso III se produce un silencio que ha llamado la atención de los estudiosos. Tanto la Crónica Albeldense como las dos versiones de la Crónica de Alfonso III, tan atentas a describir las empresas arquitectónicas de los reyes, nada dicen de la Cámara Santa. No es hasta mucho más tarde cuando es mencionada por la Historia

\footnotetext{
${ }^{31}$ E. R. Curtius, Literatura europea y Edad Media latina, México, Fondo de Cultura Académica, 1976, Tomo I, pág. 52 y ss.

$32 \quad 10,8$.

33 Crónicas Asturianas..., 7, pág. 120 y 200.

34 Crónicas Asturianas..., 7, pág. 121-22 y 201.

35 D. Mansilla Reoro, "La supuesta metrópoli de Oviedo", Hispania Sacra, núm. 8. 1955, pág. 268-69.
} 
Silense, redactada hacia 1115 , en la que se dice que Alfonso II "Hizo también una basílica de Santa Eulalia, cubierta con obra de bóveda, sobre la que se hiciese una cámara, donde en lugar más excelso fuese adorada por los fieles el arca santa" ${ }^{36}$ (Fecit quique sante Leocadie basilicam forniceo opere cumulatum, super quam fieret domus ubi celsori loco arca santa a fidelibus adoraretur) ${ }^{37}$.

Esta mención plantea diversos aspectos, analizados por Menéndez Pidal, como el hecho de que el autor de la Historia Silense destaque claramente los dos pisos de la construcción, la parte inferior construida en tiempos de Alfonso II, lo mismo que la parte alta cuya cabecera también corresponde a este soberano, y el que el resto, al parecer, estuviese en obras ${ }^{38}$. Hay que notar, además, el hecho de que esta mención de la Cámara Santa surge aquí debido a la importancia que adquieren las peregrinacions a Oviedo con las que se relacionan otros aspecos de la Historia Silense como la leyenda de la Cruz de los Ángeles que se relata por primera vez en este texto ${ }^{39}$.

El hecho de que las crónicas del ciclo de Alfonso III no mencionen la Cámara Santa no debe hacer suponer que esta obra no pueda ser atribuida a las empresas artísticas realizadas por Alfonso II y situarse en una fecha posterior correspondiente al reinado de Alfonso III ${ }^{40}$. Diversas razones parecen explicar este silencio. La Cámara Santa formaba parte del conjunto palatino construido por Alfonso II. No era una pieza independiente y aislada que mereciese como las iglesias de San Salvador, Santa Maria o San Tirso, una mención a parte. En el conjunto catedralicio de Oviedo, la Cámara Santa aparece como una pieza independiente por su antigüedad y, especialmente, por la desaparición del palacio construido por el rey Casto al que se hallada unida. Pero, en la época en que se construyó se hallaba integrada al palacio en el que cumplía la función de una "caja sagrada" destinada a la custodia del tesoro y de las reliquias de la monarquia.

En relación con este último aspecto es preciso recordar como estas capillas palatinas, cuyo modelo sigue la difundida tipología de «marty-

36 M. Gomez Moreno, Introducción a la Historia Silense, Madrid, Centro de Estudios Históricos, 1921, pág. LXXXII-LXXXIII.

${ }^{37}$ Historia Silense, Edición a cargo de J. PÉRez de Urbel y Ruiz Zorrilla, Madrid, Consejo Superior de Investigaciones Científicas, 1959, pág. 138-39.

${ }_{38}$ R. MEnÉndez PIDAL, La historiografía medieval..., pág. 25.

39 Véase J. M. Fernandez Pajares, "La Cruz de los Ángeles origen y formación de la leyenda", Miscelánea Asturiana dedicada a don Juan Uria Riu, Oviedo, Universidad de Oviedo, 1961, pág. 102-112.

${ }^{40}$ F. J. Fernández Conde, el Libro de los Testamentos de la Catedral de Oviedo, Roma, Iglesia Nacional Española, 1971, pág. 114-115. 
rium» ${ }^{41}$, tenía una integración plena en el palacio, hasta el punto de que, como ha escritor Grabar, «La ubicación topográfica entre capilla palatina y la corte real era tan íntima que la palabra "capella" servía veces para designar la cancillería o los archivos de palacio" " ${ }^{42}$. A esto se debe, con seguridad, que las cronicas no mencionen la Cámara Santa, quedando enumerada, de forma implícita, en la referencia que la Crónica Albeldense hace de los "regios palacios» (regiis palatiis) ${ }^{43}$, la versión "A Sebastian" de la Crónica de Alfonso III, al indicar que San Julián de los Prados se hallaba "distante del Palacio casi un estadio" (distantem a palatio quasi stadium unum) ${ }^{44}$ o, según la "Rotense", "bastante lejos del palacio" (necnon satis procul a palatium) ${ }^{45}$. La Cámara Santa era capilla real y cámara de Tesoros inmersa en el palacio real. Su piso superior solamente tenía acceso por una puerta de la torre ${ }^{46}$.

Pero, si el silencio en torno a la Cámara Santa es un problema que ha ocupado a los estudiosos, otras noticias transmitidas por las crónicas han sido igualmente objeto de atención y polémica. En la descripción que hace la Crónica Albeldense de los edificios construidos por Alfonso II en Oviedo, una expresión aplicada a la descripción de la iglesia de San Tirso, ha llamado constantemente la atención de los estudiosos. Al referirse a esta iglesia, erigida por Alfonso II, el cronista dice que es "edificio asombroso con muchas esquinas" (miro opere hedificio cum multis angulis fundamentavit) ${ }^{47}$. La expresión, cum multis angulis ha dado lugar a diversas suposiciones debido a que, por haber llegado a nosotros solamente parte de la cabecera, es difiicil determinar con precisión el sentido de la descripción de la crónica. Por otra parte, entre todas las crónicas que forman el ciclo de Alfonso III solamente en esa aparece esta expresión. La versión "rotense" de la Crónica de Alfonso III se limita a decir que el rey Casto «...edificó otra iglesia, la del bienaventurado mártir Tirso, cerca de la Iglesia de San Salvador..." (...etiam aliam eclesiam beatissimi Tirsi martiris prope domum sancti Salvatortis fundavit) ${ }^{48}$. Por su parte, en

${ }^{41}$ E. DYGUE, "Le Type architecturai de la Camara Santa d'Oviedo et larchitecture asturienne", Cahiers Archéologiques, VI, 1952, pág. 125-133.

${ }^{42}$ A. Grabar, Martyrium. Recherches sur le culte des reliques et l'Art crhétien antique,

Paris, A. Maisoneuve, 1946, Tomo I, pág. 563-64.

43 Crónicas Asturianas..., XV, 9, pág. 175 y 249

44 Crónicas Asturianas..., 21, pág. 141 y 215.

45 Crónicas Asturianas..., 21, pág. 214.

46 H. SCHLUNK, "El arte en torno al 800", Simposio del Beato de Liébana, Madrid 1980, pág. 147. Sobre la cuestión del problema de la datación de la Cámara Santa, véase $H$. Rodriguez Balbín, obra citada, pág. 109.

47 Crónicas Asturianas..., XV, 9, pág. 174.

48 Crónicas Asturianas..., 21, pág. 140 y 214. 
la versión corregida de esta crónica («A Sebastian»), se celebra con un énfasis particular la belleza del edificio sin hacer referencia a los aspectos formales y constructivos mencionados por la Crónica Albeldense: «construyó [...] también una tercera basílica en memoria de San Tirso, obra cuya belleza más puede admirar quien esté presente que alabarla un cronista erudito" (...necnon et tertiam baselicam in memoriam sancti Tyrsi condidit cuius operis pulcritudo plus presens potest mirare quam eruditus scriba laudare) ${ }^{49}$.

La mencionada expresión, cum multis angulis, se ha puesto en relación con diversos aspectos constructivos. Schlunk ha notado que esta expresión aludiría probablemente a la existencia de "cámaras laterales y un porche" ${ }^{50}$. Sin embargo, a Fontaine, esta expresión se le ofrece como una "fórmula enigmática» ${ }^{51}$. Por nuestra parte, pensamos que el cronista al utilizar la palabra "angulis" se limitó a tomarla de San Isidoro quien la emplea en sus Etimologías al describir las diferentes partes de los edificios. Tras analizar el alcance etimológico de las palabras "cimientos" (fundamentum) y "paredes" (paries) dice que "Angulus (rincón) es el punto en que se juntan dos paredes" (Angulus, quod duos parietes in unum coniugat) ${ }^{52}$. El término "angulis", cuya derivación de la obra de San Isidoro acredita, una vez más, la fuerte influencia ejercida por sus escritos en el autor de la Crónica Albelda ${ }^{53}$, constituye una clara referencia a la composición y estructura volumétrica del edificio, más que a un elemento constructivo concreto como los contrafuertes que eran un componente habitual en los edificios erigidos por el rey Casto y sus sucesores ${ }^{54}$. En este sentido, el cronista bien puede aludir, también, además de a los ángulos que formarian las cámaras anexas y a la distribu-

49 Crónicas Asturianas..., 21, pág. 139, 141 y 215.

50 H. SChlunk, Arte visigodo. Arte Asturiano, pág. 335; le sigue A. BONet Correa, obra citada, pág. 98. En un sentido parecido se pronuncia J. M. PITA ANDRADE, obra citada, pág. 15 , al suponer que se trata de la referencia a un edificio "que se destacaría tal vez por su planta enriquecida con diversas piezas anexas".

51 El Prerrománico, Madrid, Ediciones Encuentro, 1981, pág. 311. Le sigue J. L. Mo. RALEJo, Crónicas Asturianas, pág. 248-49 que traduce literalmente "angulos".

52 Etymologiarum, XV, 8, 4. Cito por la edición de J. Oroz Reta y M. A. Marcos Casquero, Etimologias, Madrid, B.A.C., 1983, 2 vols.

${ }_{53}$ M. GOMEz MOReno, Las primeras crónicas..., pág. 568 , notó el manejo y copia de las fuentes isioiorianas por el autor de la Crónica Albeldense; también, M. C. DiAz y Diaz, "La historiografía hispana desde la invasión árabe hasta el año $1000 "$, Settimane de Estudio del Centro Italiano sull'Alto Medievo, XVII, La storiografia altomedievale, I, Spoleto, 1970, pág. 326 y ss; A. BARBero y M. VIGll, La historiografía..., pág. 239; J. I. RUIz DE LA PENA, "La cultura ovetense del siglo IX", Crónicas Asturianas..., pág. 33 y ss.

54 H. SCHLUNK, obra citada, pág. 335. 
ción de su cabecera ${ }^{55}$, a las formas que presentaría el escalonamiento en altura de sus componentes ${ }^{56}$.

La mención, en cambio, que hace de la iglesia de San Tirso la versión "A Sebastian" de la Crónica de Alfonso III es muy distinta y ofrece un aspeco que nos interesa destacar. Cuando el cronista dice que es "obra cuya belleza más puede admirar quien esté presente que alabarla un cronista erudito" (cuius operis pulcritudo plus presens potest mirare quam eruditus scriba laudare) ${ }^{57}$ hace una valoración estética del edificio que contrasta con la suposición, generalmente admitida, de la estimación exclusivamente simbólica y religiosa que se ha supuesto en los hombres de la Edad Media ${ }^{58}$ con respecto a las obras de arte.

Igualmente el interés por destacar el carácter innovador de determinadas soluciones constructivas adquiere un relieve especial en las referencias relativas a Santa María de Naranco y San Miguel de Lillo, construidos por Ramiro I (842-850), cerca de Oviedo. Se trata de una valoración de los aspectos constructivos, común a todas las crónicas del ciclo de Alfonso III, que constrasta con las descripciones de edificios del rey Casto en las que, como hemos visto, se alaba preferentemente su belleza y la importancia de su decoración o "venustas". El autor de la Crónica Albeldense, al referirse a los edificios construidos por este monarca, aunque lo hace sin renunciar al estilo escueto que le caracteriza, no omite la impresión que le produce su forma de abovedamiento: “En el lugar de Liño construyó una iglesia y palacios, con admirable obra de bóveda." (In locum Ligno eclesiam et palacia arte fornicea mire construxit) ${ }^{59}$. Más explícito resulta en la alabanza de las novedades constructivas la versión "rotense" de la Crónica de Alfonso III: "...edificó muchos edificios de piedra y mármol, sin vigas, con obra de abovedado, en la falda del Monte Naranco, a sólo dos millas de Oviedo" (multa edificia ex murice et marmore sine lignis opere forniceo in latere montis Naurantii duo tantum miliaris procul ab Oueto edificauit) ${ }^{60}$.

${ }_{55}$ Véase F. Redondo Cadenas, San Tirso de Oviedo a través de la Historia, Oviedo, Instituto de Estudios Asturianos, 1986.

56 Así apunta J. YARZA LUACES, Arte y Arquitectura en España 500-1250, Madrid, Ediciones Cátedra, 1979, pág. 46, al suponer que la expresión «parece poder explicarse por los diferentes planos de la cabecera y, posiblemente, por el juego de vólumenes a diferentes alturas.

${ }_{57}$ Crónicas Asturianas..., 21, pág. 141 y 215.

58 M. SchapIRo, "Sobre la actitud estética en el arte romántico", Estudios sobre el romántico. Traducción M. L. Balseiro, Madrid, Alianza Editorial, 1985, pág. 13 y ss.

59 Crónicas Asturianas..., XV, 10, pág. 175 y 249

6rónicas Asturianas..., 24, pág. 144 y 216. 
Estas referencias a los edificios construidos por Ramirol merecen ser estudiadas con cierto detenimiento. El cronista destaca, además de su condición de edificios abovedados (opere forniceo), que fueron construidos sin utilizar vigas, es decir, prescindiendo del empleo de techumbres de madera. De los edificios a que se refieren las crónicas solamente se conservan dos, Santa María de Naranco y San Miguel de Lillo y éste en estado fragmentario. De ambos, solamente del segundo, a pesar de que ha llegado a nosotros incompleto, podemos afirmar que se construyó sin utilizar ningún tipo de cubrición de madera. Pues, en el palacio de Santa María de Naranco, se cubren con madera las cámaras de los extremos del cuerpo inferior sirviendo, a la vez, como suelo a los miradores.

Esta mención se justifica, además, por la novedad que ofrecía este sistema de cubrición en relación con las iglesias del periodo de Alfonso II. En éstas, a excepción de los ábsides de la cabecera que se cubrian con bóveda de cañón, el resto del edificio lo hacia con una techumbre de madera. En San Julián de los Prados puede verse hoy este sistema mixto de cubrición que se utilizó también, al parecer, en otras iglesias de la sedes regia como la catedral de San Salvador y el panteón regio de Santa Maria ${ }^{61}$.

Por una noticia relativa a este último edificio que nos transmite la Historia Silense, sabemos que Alfonso II lo construyó con una estructura similar a la de San Salvador: "llevó a efecto un santuario de la bienaventurada madre de Dios y virgen Maria, con pareja estructura y tres cabeceras" ${ }^{62}$ (aulam beate Dei genitricis et virginis Marie pari cemento cum tribus capitibus) ${ }^{63}$. $\mathrm{Y}$, por la preciosa descripción que nos ha transmitido Ambrosio de Morales, sabemos que la iglesia de Santa María estaba cubierta por una techumbre de madera a excepción de las capillas de la cabecera que eran abovedadas: "Estas tres Capillas están solamente de bóveda, y toda la iglesia muy pobremente techada, que parece que no se hizo mas de lo que fue menester para solamente cubrirla, y despues labrar debaxo" ${ }^{64}$. Este testimonio acredita como este modelo de iglesia, similar al de Santullano, fue una tipología común a los principales edifi-

61 F. Selgas, “La primitiva basílica de Santa María del Rey Casto de Oviedo y su Real panteón”, Boletín de la Real Academia de la Historia, XVI, 1890, pág. 177-312. Véase, de este mismo autor "La Basilica del Salvador de Oviedo de los siglos VIII y IX", Boletín de la Sociedad Española de Excursiones, XVI, 1908, pág. 162-200.

62 M. Gómez MOREno, Introducción a la Historia Silense, pág. LXXXIII.

63 Historia Silense, edición a cargo de J. Pérez de Urbel y A. Ruiz Zorrilla, pág. 138.

64 Crónica, Libro XIII, Cap. XL, pág. 177. 
cios construidos por Alfonso II. Incluso la Cámara Santa tuvo originariamente una forma de cubrición mixta, con bóveda en la cripta y en el ábside del piso superior y con madera, antes de la reforma del siglo XII, el cuerpo de la nave. Por todo ello, no ha de extrañar el asombro y la admiración que suscitó en los cronistas la realización de edificios completamente abovedados.

Con independencia de esta valoración de ciertos aspectos constructivos, el énfasis con que son ensalzados en una de las crónicas introduce unos planteamientos cuyo alcance y significación deben ser analizados con detenimiento. Me refiero a la mención que se hace en la versión corregida ("A Sebastian») de la Crónica de Alfonso III de uno de los edificios construidos por Ramiro I: «Entretanto el dicho rey fundó una iglesia en memoria de Santa María, en la falda del Monte Naranco, distante de Oviedo dos millas, de admirable belleza y hermosura perfecta y, para no referirme a otras de sus hermosuras, tiene una bóveda apoyada en varios arcos, y está construida solamente con cal y piedra; si alguien quisiera ver un edificio similar a ése, no lo hallará en España" (Interea supra dictus rex ecclesiam condidit in memoriam sancte Marie in latere montis Naurantii, distantem ab Oueto duorum milia passuum mire pulcritudinis perfecteque decoris et, ut alia decoris eius taceam, cum pluribus centris forniceis sit concamerata, sola calce et lapide constructa; cui si aliquis edificium consimilare voluerit, in Sapania non inueniet) ${ }^{65}$.

La iglesia a la que se refiere el cronista no es otra que la actual de San Miguel de Lillo, dedicada inicialmente a Santa Maria y cuya ara paso al palacio que fue convertido después en iglesia de Santa María ${ }^{66}$. Actualmente el ara se conserva en el Museo Arqueológico de Oviedo, habiéndose dejado en el palacio una copia. La descripción de la crónica coincide, además, en todos sus aspectos, con las caraterísticas de la iglesia de San Miguel de Lillo, al destacar su construcción realizada solamente con cal y piedra (sola calce et lapide constructa), la novedad de la totalidad de su estructura abovedada y el empleo de arcos fajones (cum pluribus centris forniceis). Que este sistema de abovedamiento llamó la atención del cronista por ser algo desconocido hasta entonces es evidente; al menos, lo que resultaba nuevo era, según hemos apuntado, la utilización de la bóveda reforzada con fajones como sistema "exclusivo de cubrición».

65 Crónicas Asturianas..., 24, pág. 145 y 217.

66 M. Berenguer, "Puntualizaciones sobre los edificios ramirenses del Naranco (Oviedo)", Anuario de Estudios Medievales, 1972-73, pág. 395-403. 
En esta descripción existen, además, otros aspectos que, en nuestra opinión, revelan algunos de los propósitos que movieron a Alfonso III a impulsar el ciclo historiográfico de su nombre. Menéndez Pidal, para quien las menciones artísticas de las crónicas adquieren "el aire de una guia del viajero, un Baedeker del siglo Ix, que lleva como de la mano la atención del forastero en Oviedo para dirigirla hacia cosas notables" ${ }^{67}$, ha interpretado la valoración de los edificios que se hace en el ciclo historiográfico de Alfonso III como la idea de que «Asturias no solo quiere continuar a Toledo en el linaje de sus reyes y en el desarrollo de la historiografía nacional, sino en la cutura toda” ${ }^{68}$. Sin embargo, creemos que la intención del cronista al alabar de esta forma la iglesia construida por Ramiro I, va más allá de un deseo de subrayar la idea de la mencionada continuidad visigoda a que antes hicimos mención.

En el texto transcrito se pone de manifiesto una idea de superación con respecto a lo visigodo. Pues, "Spania", en la época en la que se escribieron las crónicas significaba el territorio que se extendía al sur de las fronteras del reino asturiano. Esta afirmación, además, tiene lugar en un momento de expansión en el que Alfonso III se plantea la posibilidad de trasladar la corte a León ${ }^{69}$. Lo cual, incluso, parece confirmarlo el alcance de los programas artísticos llevados a cabo por este soberano. La Crónica Albeldense dice, refiriéndose a las empresas artísticas de Alfonso III, que "Todos los templos del Señor son restaurados por este príncipe, y en Oviedo se edifica una ciudad con palacios reales" ( $A b$ hoc principe omnia templa Domini restaurantur et ciuitas in Ouetao cum regias aulas hedificatur) ${ }^{70}$. Las obras emprendidas por este soberano en la sedes regia no tuvieron un alcance comparable al de los programas de Alfonso II. Además de un nuevo palacio consistieron en obras de fortificación destinadas a consolidar y conservar la "hierápolis" preexistente, entendiéndola como una sedes regia cerrada y terminada.

A este respecto, la idea que subyace en la mencionada referencia de la crónica no puede ser más elocuente, acreditando, en lo artístico la idea de que se ha producido la mencionada traslatio justificada, desde un punto de vista teológico y político, por el supuesto de la continuidad del reino asturiano con respecto al visigodo, según se intenta acreditar

67 La historiografía medieval..., pág. 21-22.

68 R. MENÉnDez PIDAL, obra citada, pág. 19.

69 Sobre este aspecto de la crónica véas a A. UBiETO ARTETA, "La redacción "ovetense" de la Crónica de Alfonso Ill", Symposium sobre cultura asturiana..., pág. 368.

${ }^{70}$ Crónicas Asturianas..., XV, 13, pág. 177-178 y 252. 
en las crónicas ${ }^{71}$. Pero, al mismo tiempo, esta traslatio no se plantea como una continuidad estática sino como la utopía de una superación en la que la imagen de la arquitectura regia asume el papel de uno de los protagonistas del mito.

71 R. Menendez PIdal, Historia de España..., pág. X-XI. 


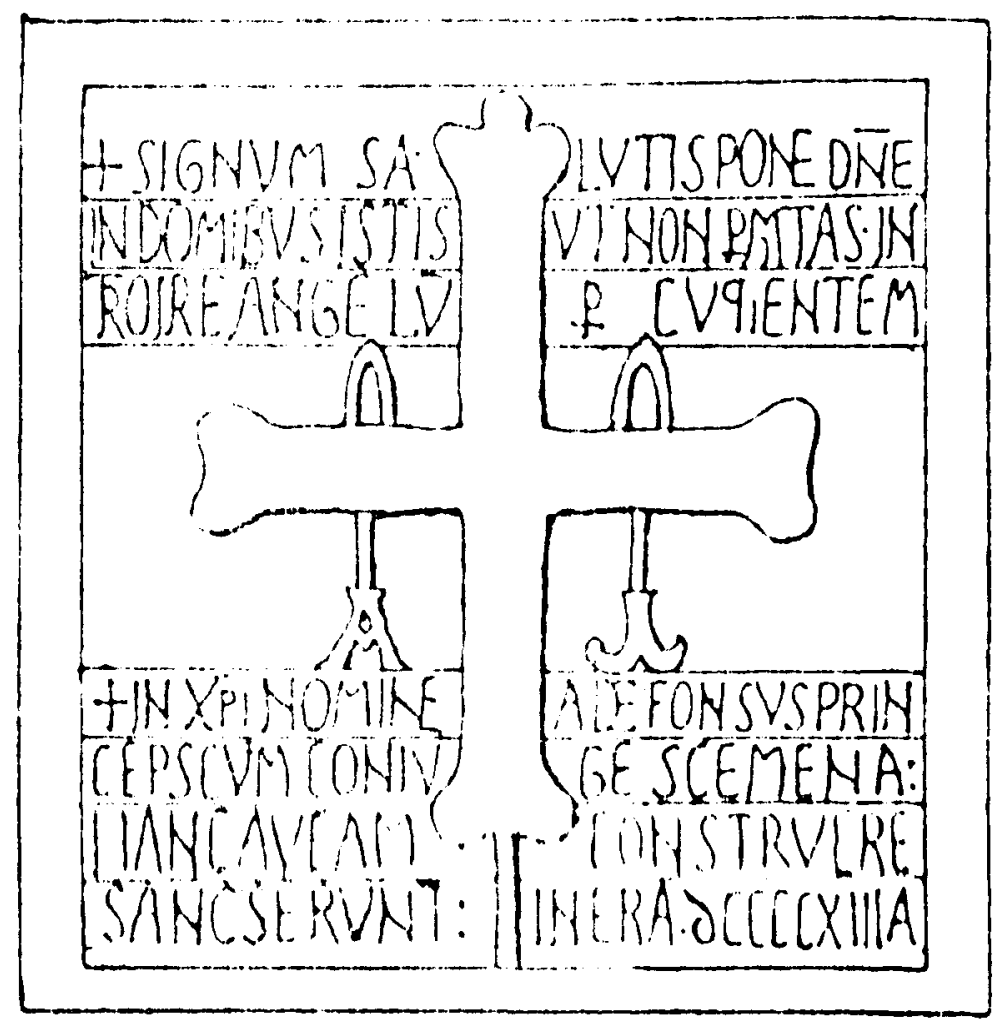

Fig. 1. Inscripción del Palacio de Alfonso III.

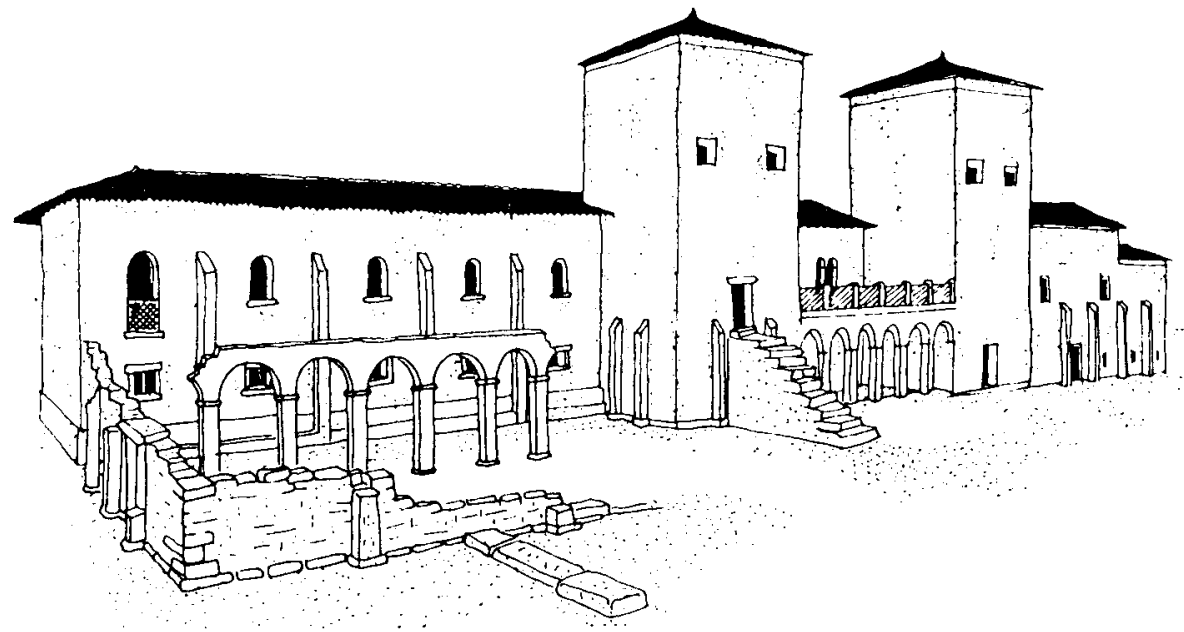

Fig. 2. Fachada sur del Palacio de Alfonso II. 

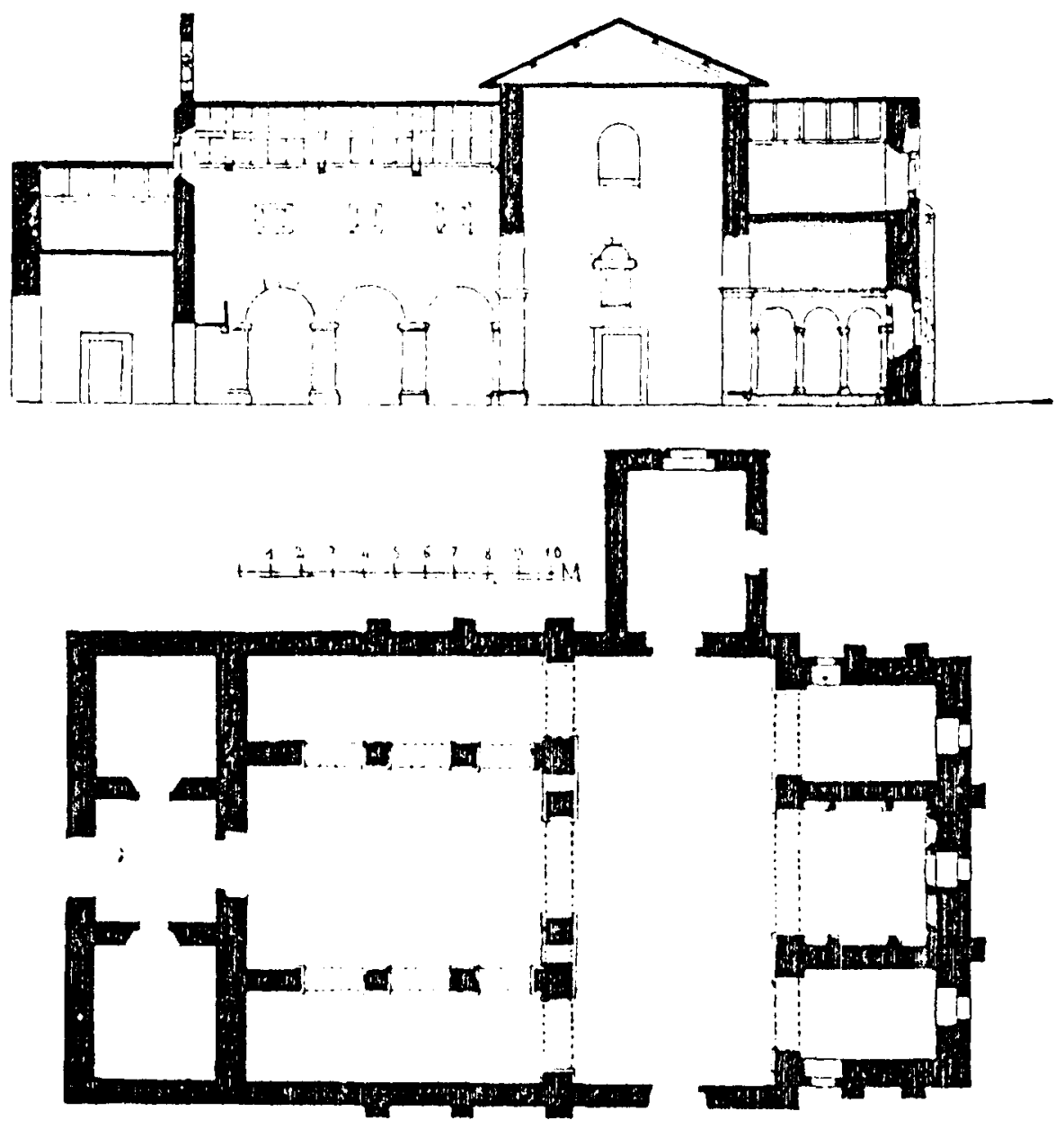

Fig. 3. Basílica de Santullano. 


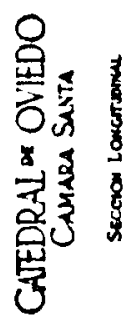

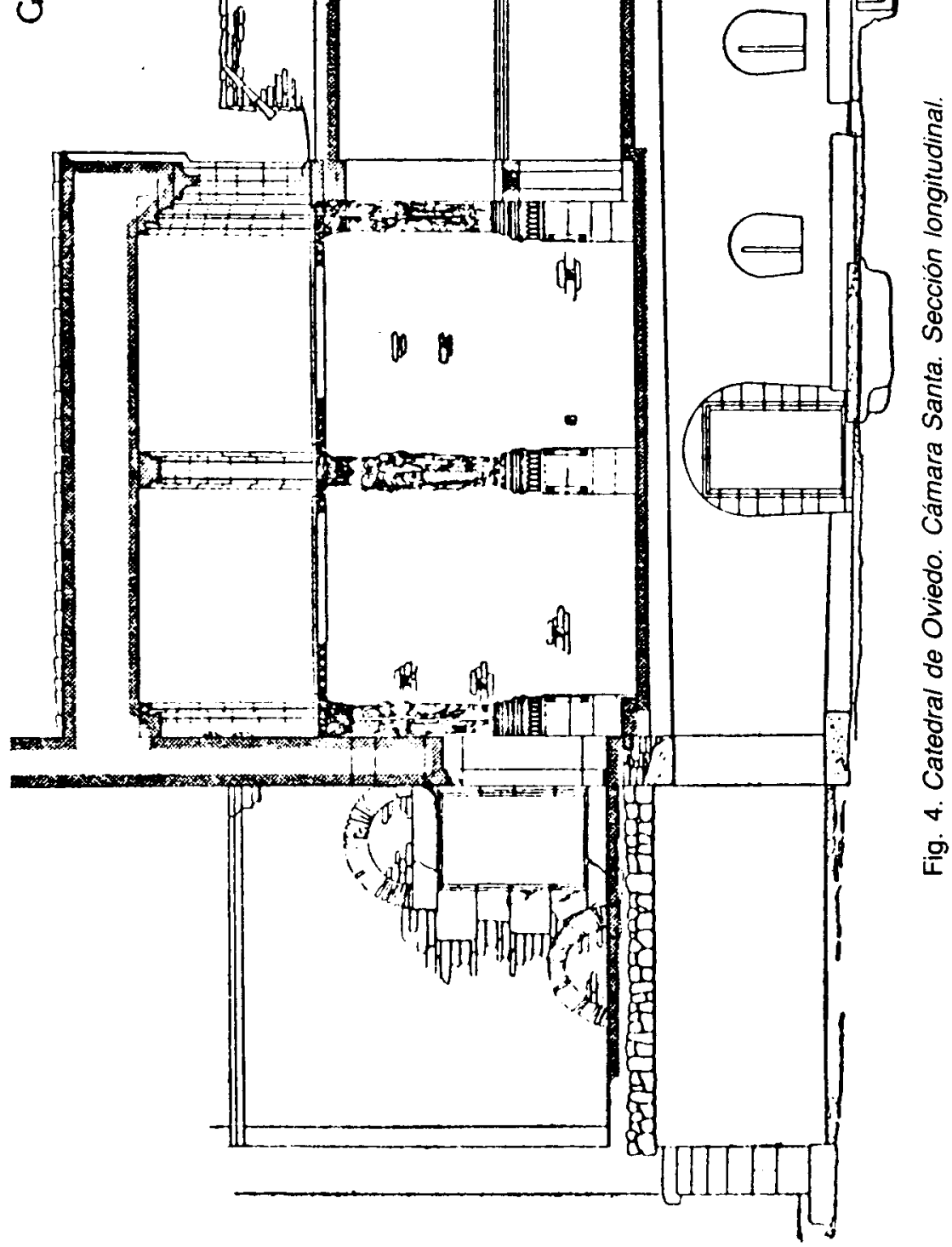




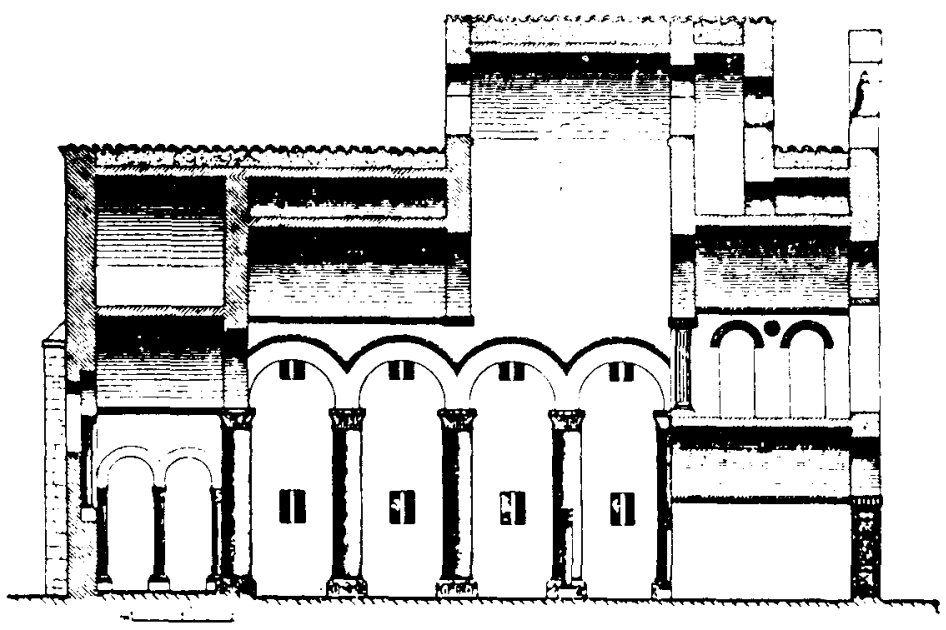

Fig. 5. Reconstrucción de la iglesia de San Miguel de Lillo (según A. del Llano).

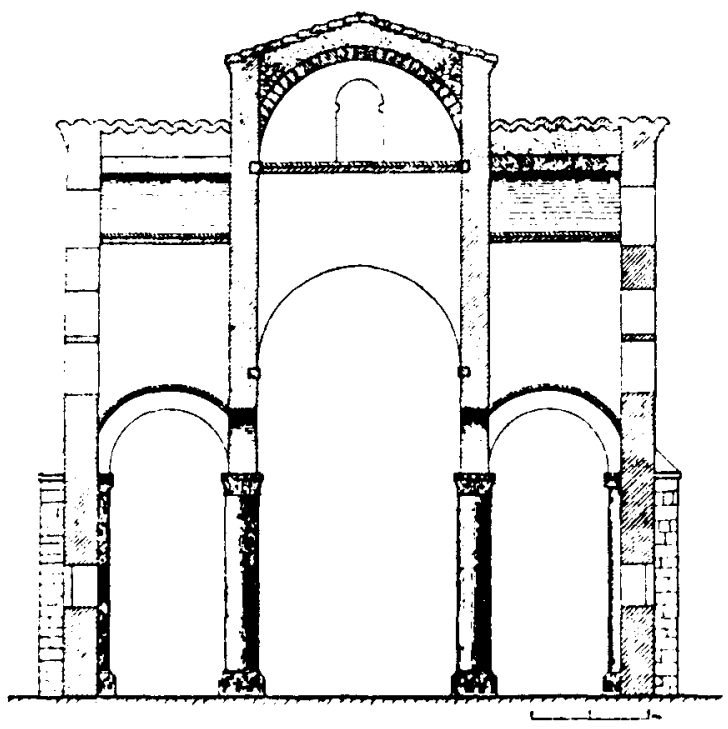

Fig. 6. Reconstrucción de la iglesia de San Miguel de Lillo (según A. del Llano). 


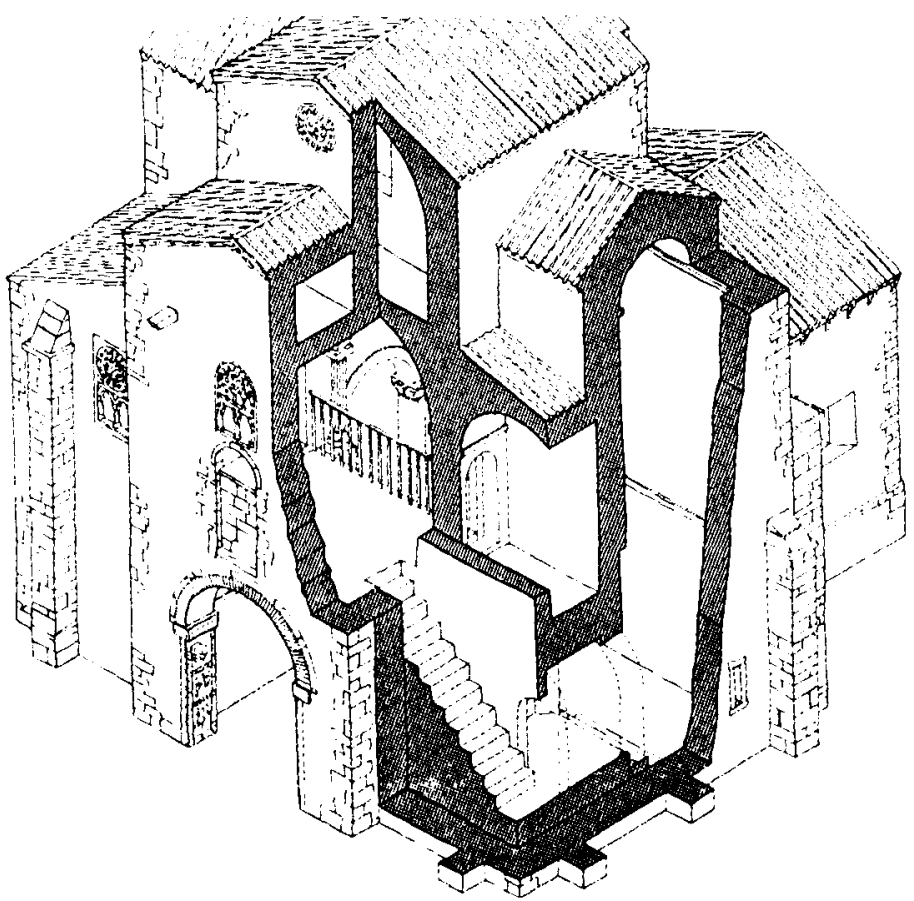

Fig. 7. Alzado de San Miguel de Lillo (Dibujo de Miguel Cores).

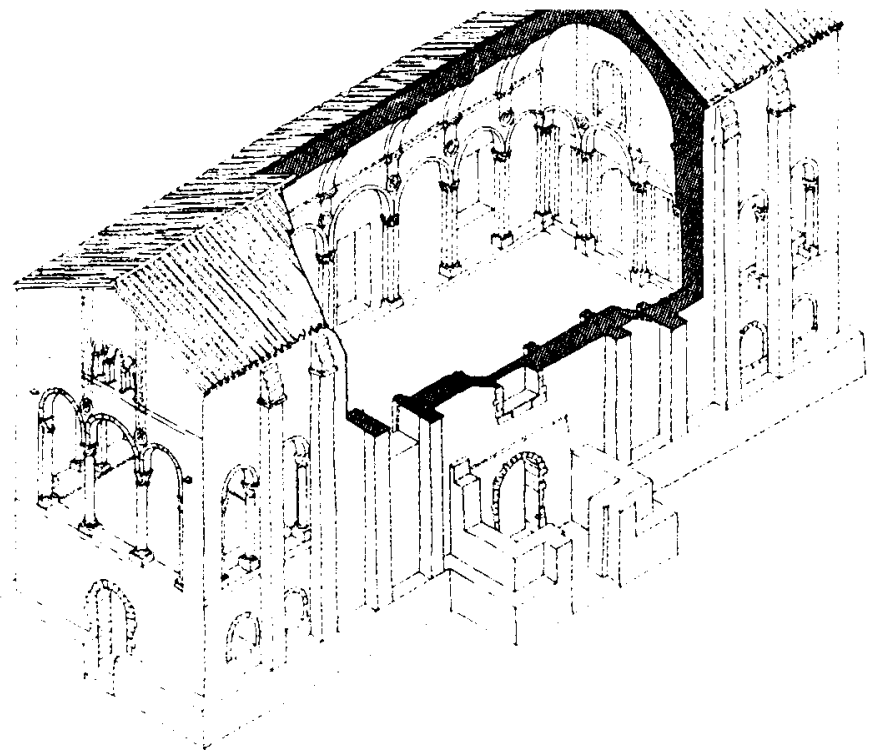

Fig. 8. Alzado de Santa María del Naranco (Dibujo de Miguel Cores). 
La imagen de la arquitectura asturiana de los siglos vill y ix...

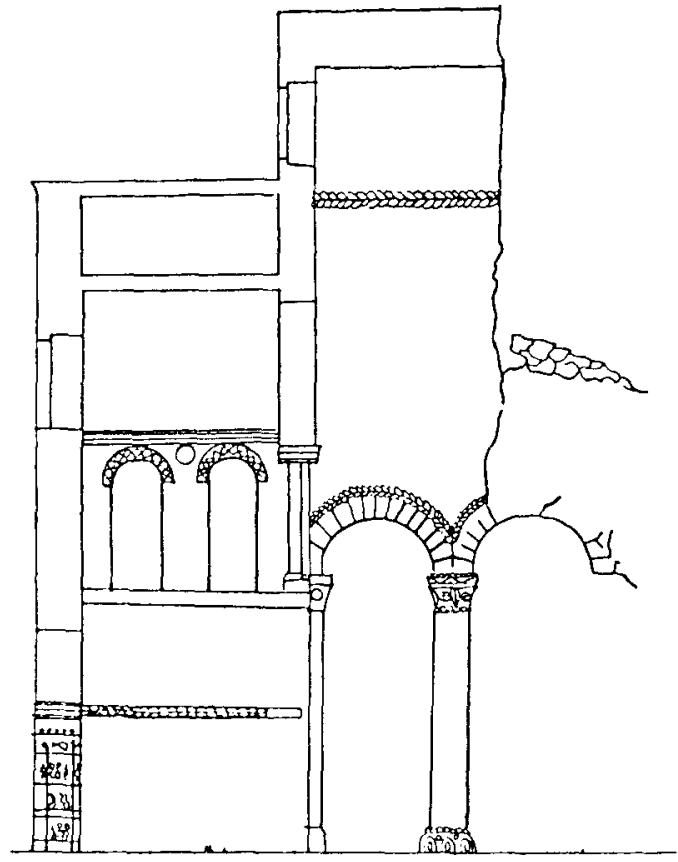

Fig. 9. Tribuna de San Miguel de Lillo.

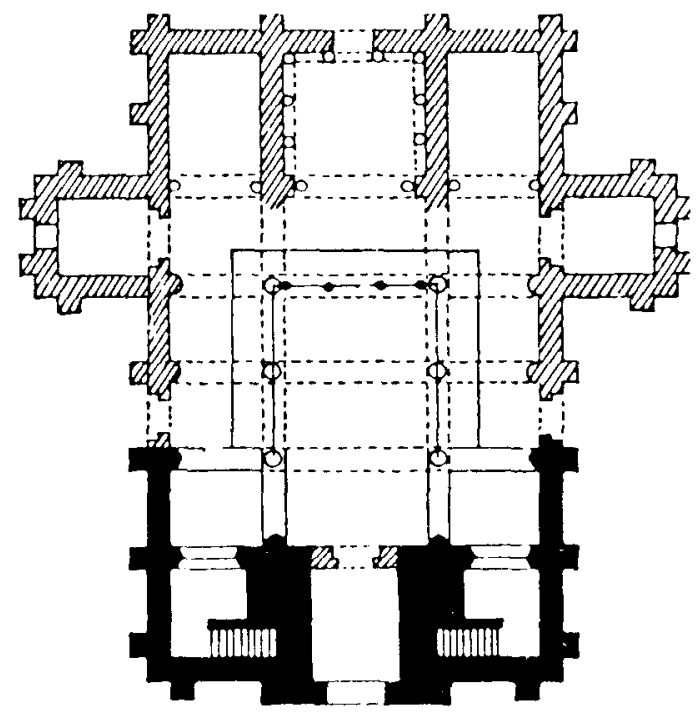

Fig. 10. Reconstrucción de la planta de San Miguel de Lillo. 


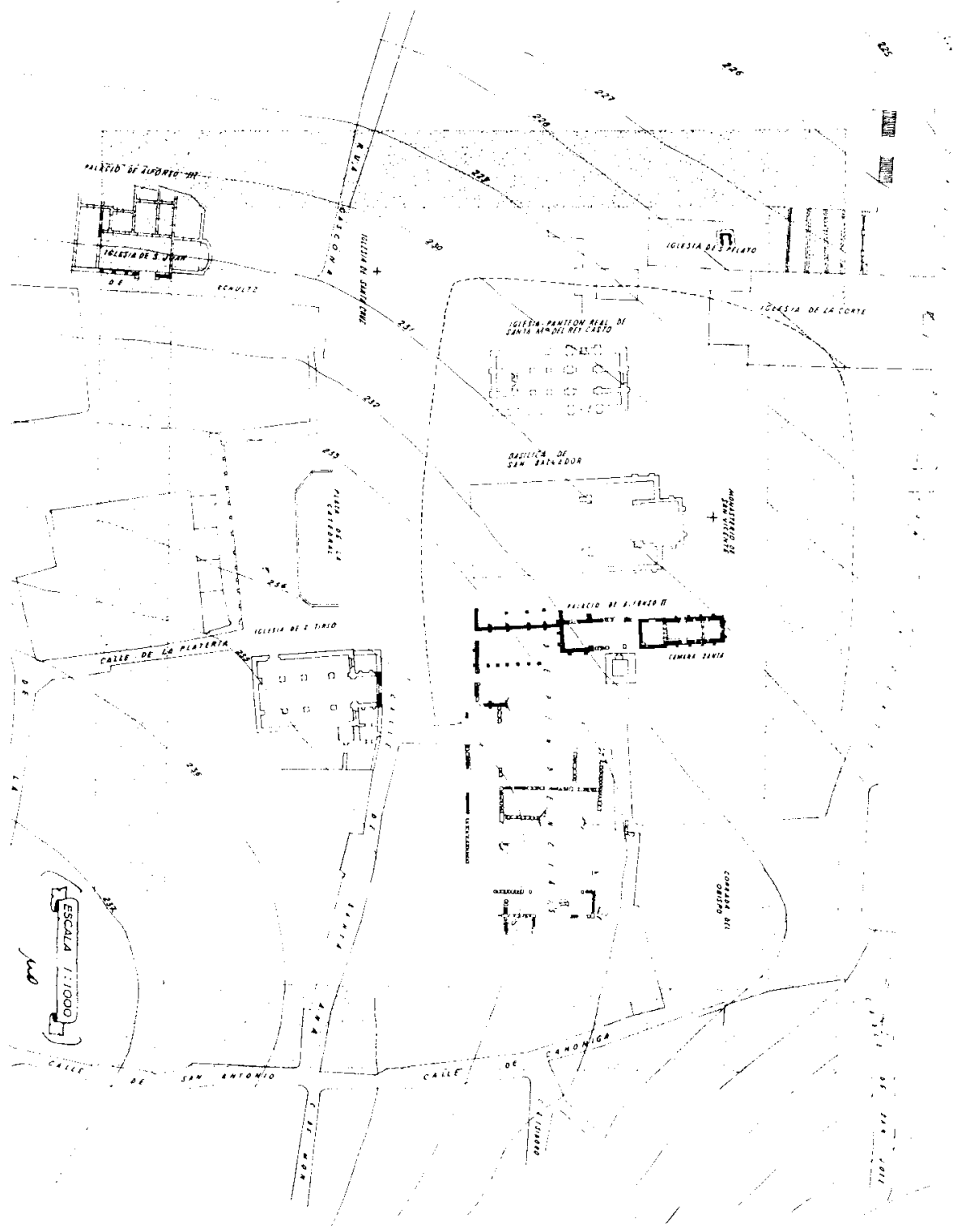

Fig. 11. Plano de Oviedo (según Uria). 